\title{
Lag time determination in DEC measurements with PTR-MS
}

\author{
R. Taipale ${ }^{1}$, T. M. Ruuskanen ${ }^{1,2}$, and J. Rinne ${ }^{1}$ \\ ${ }^{1}$ University of Helsinki, Department of Physics, P.O. Box 64, 00014 University of Helsinki, Finland \\ ${ }^{2}$ University of Innsbruck, Institute of Ion Physics and Applied Physics, Technikerstr. 25, 6020 Innsbruck, Austria
}

Received: 8 December 2009 - Published in Atmos. Meas. Tech. Discuss.: 8 February 2010

Revised: 15 June 2010 - Accepted: 30 June 2010 - Published: 7 July 2010

\begin{abstract}
The disjunct eddy covariance (DEC) method has emerged as a popular technique for micrometeorological flux measurements of volatile organic compounds (VOCs). It has usually been combined with proton transfer reaction mass spectrometry (PTR-MS), an online technique for VOC concentration measurements. However, the determination of the lag time between wind and concentration measurements has remained an important challenge. To address this issue, we studied the effect of different lag time methods on DEC fluxes. The analysis was based on both actual DEC measurements with PTR-MS and simulated DEC data derived from high frequency $\mathrm{H}_{2} \mathrm{O}$ measurements with an infrared gas analyzer. Conventional eddy covariance fluxes of $\mathrm{H}_{2} \mathrm{O}$ served as a reference in the DEC simulation. The individual flux measurements with PTR-MS were rather sensitive to the lag time methods, but typically this effect averaged out when the median fluxes were considered. The DEC simulation revealed that the maximum covariance method was prone to overestimation of the absolute values of fluxes. The constant lag time methods, one based on a value calculated from the sampling flow and the sampling line dimensions and the other on a typical daytime value, had a tendency to underestimate. The visual assessment method and our new averaging approach utilizing running averaged covariance functions did not yield statistically significant errors and thus fared better than the habitual choice, the maximum covariance method. Given this feature and the potential for automatic flux calculation, we recommend using the averaging approach in DEC measurements with PTR-MS. It also seems well suited to conventional eddy covariance applications when measuring fluxes near the detection limit.
\end{abstract}

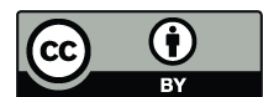

Correspondence to: R. Taipale (risto.taipale@helsinki.fi)

\section{Introduction}

Volatile organic compounds (VOCs) affect tropospheric chemistry mainly through their reactions with $\mathrm{OH}, \mathrm{NO}_{3}$, and $\mathrm{O}_{3}$ (e.g. Koppmann, 2007). Some of them are deemed major contributors or inhibitors to aerosol particle formation and growth (e.g. Hoffmann et al., 1997; Claeys et al., 2004; Hallquist et al., 2009; Kiendler-Scharr et al., 2009), thus making VOC measurements essential for the current climate change research. Globally, natural VOC emissions (about $1150 \mathrm{Tg}$ (C) per year) are estimated approximately ten times higher than emissions due to human activity (Guenther et al., 1995).

Micrometeorological flux measurements with the eddy covariance method have yielded fundamental information on ecosystem scale VOC emissions (e.g. Guenther and Hills, 1998; Shaw et al., 1998; Karl et al., 2001, 2002; Warneke et al., 2002; Spirig et al., 2005; Brunner et al., 2007; Rinne et al., 2007). Many of these measurements have relied on an approach called disjunct eddy covariance (DEC; Rinne et al., 2001; Karl et al., 2002), which has usually been combined with proton transfer reaction mass spectrometry (PTR-MS), an online technique for measuring VOC concentrations (e.g. Lindinger et al., 1998; de Gouw and Warneke, 2007; Blake et al., 2009). In addition to theoretical considerations and data simulations (e.g. Kaimal and Gaynor, 1983; Lenschow et al., 1994), field studies have shown that DEC is a reliable and robust method for trace gas flux measurements (Rinne et al., 2008; Turnipseed et al., 2009; Hörtnagl et al., 2010).

Both DEC and the conventional eddy covariance (EC) method have the same basic principle. The flux is calculated as the covariance of the vertical wind speed and the VOC concentration. In the conventional approach, both variables are measured with fast response instruments at a high frequency, normally $10-20 \mathrm{~Hz}$. In the disjunct version, short VOC samples of $0.1-0.5 \mathrm{~s}$ are taken at intervals of $1-30 \mathrm{~s}$, resulting in a disjunct time series. The wind velocity is measured at a high frequency also in DEC. Due to the typical

Published by Copernicus Publications on behalf of the European Geosciences Union. 
response times of less than $0.5 \mathrm{~s}$, the present PTR-MS instruments are adequate for multi-compound DEC measurements with continuous sampling flow, sometimes referred as virtual DEC (Karl et al., 2002). Slower instruments require an additional intermediate sample container for disjunct sampling (Rinne et al., 2001), or alternatively, high frequency corrections in the post-processing of flux data (Davison et al., 2009).

When measuring gas or particle fluxes, a major pragmatic challenge in EC and DEC is to determine the lag time between wind and concentration measurements, i.e., the delay caused by the sample transit time through the sampling line. Once the lag time has been determined, the time series can be synchronized, and the flux value is given by the covariance derived from the matched time series. A straightforward lag time calculation based on the sampling flow and the sampling line dimensions is an inadvisable option as the flow often varies, at least during an extended measurement period (e.g. Shimizu, 2007). Further, the lag time appears to depend on the compound, an unpleasant feature for VOC flux measurements. This is suggested by the compound-specific attenuation of turbulent fluctuations in the sampling line (e.g. Su et al., 2004).

The prevalent solution is to calculate the covariance as a function of lag time, and then determine the maximum absolute value of the covariance within a reasonable lag time window (e.g. McMillen, 1988; Aubinet et al., 2000). This method can be automated reliably if the maximum is distinct, like in most EC measurements of $\mathrm{CO}_{2}$ and $\mathrm{H}_{2} \mathrm{O}$ for instance. However, noisy covariance functions, common in DEC measurements, require usually visual judgement (Rinne et al., 2007; Davison et al., 2009). Such manual assessment is somewhat dependent on the person, prone to human errors, and burdensome, but it may be the only viable option when measuring small VOC fluxes. Still, an automated and objective regime would systematize and hasten data processing.

In addition to the challenging lag time determination, noisy covariance functions inflict other difficulties on flux calculation. When the lag time is derived from the maximum absolute covariance, a systematic overestimation of the absolute flux is possible. Of course, this flaw also afflicts EC measurements relying on such lag time method, but its impact is even more harmful in DEC where the signal-to-noise ratio tends to be lower.

This paper addresses the lag time problem, a timely conundrum for many research groups as the combination of DEC and PTR-MS has emerged as a popular tool in VOC flux measurements. We present an explicit comparison of five lag time methods and illustrate how they affect fluxes measured with DEC. We consider two variants of the constant lag time approach. Both of them are based on preset values, one calculated from the sampling flow and the sampling line dimensions, the other representing a typical daytime value deduced from measurements with distinct covariance function maxima. We also evaluate the maximum covariance method, which is the habitual choice in EC, our new averaging approach, and the visual assessment method. The averaging approach strives to facilitate automated lag time determination by reducing the noise in a covariance function. Although our new method is mainly intended for DEC measurements with PTR-MS, it might be useful for any application affected by noisy covariance functions, i.e., when measuring fluxes near the detection limit. One current application could be EC measurements with the novel PTR-MS instrument equipped with a time-of-flight mass analyzer (e.g. Blake et al., 2009; Müller et al., 2010).

To assess the performance of different lag time methods, we first look at high frequency $\mathrm{H}_{2} \mathrm{O}$ measurements by an infrared gas analyzer. In the absence of a direct reference for our DEC measurements, we simulate them by adding noise to the original $\mathrm{H}_{2} \mathrm{O}$ data and then converting it into a disjunct time series. This manipulated $\mathrm{H}_{2} \mathrm{O}$ signal is thought to resemble a typical VOC measurement by PTR-MS. EC measurements of $\mathrm{H}_{2} \mathrm{O}$ fluxes are regarded as a reference for this DEC simulation.

Next, we probe how the lag time methods affect actual DEC fluxes measured by PTR-MS. Given the good correlation between the PTR-MS water cluster ion signal, detected at $37 \mathrm{amu}$ (M37), and the ambient $\mathrm{H}_{2} \mathrm{O}$ concentration (Ammann et al., 2006), contrasting M37 fluxes with the reference $\mathrm{H}_{2} \mathrm{O}$ fluxes can shed light on the lag time problem. Finally, we illustrate the influence of lag time determination on fluxes of two classic subjects in PTR-MS studies, methanol and monoterpenes.

\section{Methods}

\subsection{Measurements}

The SMEAR II (Station for Measuring EcosystemAtmosphere Relations II) station of the University of Helsinki served as the measurement site (for a review, see Hari and Kulmala, 2005). It was situated at a rather homogeneous 45-year-old Scots pine (Pinus sylvestris) dominated forest in southern Finland $\left(61^{\circ} 51^{\prime} \mathrm{N}, 24^{\circ} 17^{\prime} \mathrm{E}, 180 \mathrm{~m}\right.$ a.s.l.). The measurements were performed in 9-14 August 2007.

The procedure of Rinne et al. (2007) was followed in our DEC measurements with the continuous sampling flow approach. The setup consisted of a sonic anemometer (Gill Instruments Ltd., Solent HS1199) and a proton transfer reaction mass spectrometer (PTR-MS, Ionicon Analytik GmbH). The flux measurement height was $22 \mathrm{~m}$, about $6 \mathrm{~m}$ above the forest canopy. The heated sampling line was $30 \mathrm{~m}$ long, $8 \mathrm{~mm}$ in inner diameter, holding a continuous flow of $17.51 \mathrm{~min}^{-1}$, and made of Teflon (PTFE). A side flow of $87 \mathrm{ml} \mathrm{min}^{-1}$ was taken into the PTR-MS through a PTFE tube, which was $1.3 \mathrm{~m}$ in length and $1.6 \mathrm{~mm}$ in inner diameter. The wind velocity was measured at $10 \mathrm{~Hz}$ and the data were saved on a different computer than the PTR-MS data. 
Table 1. PTR-MS measurement cycle in the DEC measurements, the compounds contributing to the measured masses, and the PTRMS integration times. The cycle length was $6.6 \mathrm{~s}$.

\begin{tabular}{|c|c|c|c|}
\hline \multicolumn{2}{|c|}{$\begin{array}{l}\text { Protonated mass [amu] and } \\
\text { contributing compound(s) }\end{array}$} & \multirow{2}{*}{$\begin{array}{l}\text { Formula } \\
\mathrm{H}_{2}{ }^{18} \mathrm{O}^{\mathrm{a}}\end{array}$} & \multirow{2}{*}{$\begin{array}{c}\begin{array}{c}\text { Dwell time } \\
\text { [s] }\end{array} \\
0.1\end{array}$} \\
\hline 21 & water isotopes & & \\
\hline 31 & formaldehyde & $\mathrm{CH}_{2} \mathrm{O}$ & 0.5 \\
\hline 33 & methanol & $\mathrm{CH}_{4} \mathrm{O}$ & 0.5 \\
\hline 37 & water cluster & $\left(\mathrm{H}_{2} \mathrm{O}\right)_{2}$ & 0.05 \\
\hline 45 & acetaldehyde & $\mathrm{C}_{2} \mathrm{H}_{4} \mathrm{O}$ & 0.5 \\
\hline 59 & acetone & $\mathrm{C}_{3} \mathrm{H}_{6} \mathrm{O}$ & 0.5 \\
\hline 69 & $\begin{array}{l}\text { isoprene } \\
\text { methylbutenol fragment }\end{array}$ & $\mathrm{C}_{5} \mathrm{H}_{8}$ & 0.5 \\
\hline 81 & $\begin{array}{l}\text { monoterpene fragments } \\
\text { hexenal fragment }\end{array}$ & & 0.5 \\
\hline 87 & methylbutenol & $\mathrm{C}_{5} \mathrm{H}_{10} \mathrm{O}$ & 0.5 \\
\hline 99 & hexenal & $\mathrm{C}_{6} \mathrm{H}_{10} \mathrm{O}$ & 0.5 \\
\hline 101 & $\begin{array}{l}\text { cis-3-hexenol } \\
\text { hexanal }\end{array}$ & $\begin{array}{l}\mathrm{C}_{6} \mathrm{H}_{12} \mathrm{O} \\
\mathrm{C}_{6} \mathrm{H}_{12} \mathrm{O}\end{array}$ & 0.5 \\
\hline 113 & & & 0.5 \\
\hline 137 & monoterpenes & $\mathrm{C}_{10} \mathrm{H}_{16}$ & 0.5 \\
\hline
\end{tabular}

a the most abundant isotope

The PTR-MS measurement cycle lasted $6.6 \mathrm{~s}$ and contained 13 masses which were measured successively (Table 1 ). The sampling time was $0.5 \mathrm{~s}$ for each VOC-related mass, $0.1 \mathrm{~s}$ for the primary ion isotopes, and $0.05 \mathrm{~s}$ for the water cluster ions. Also the vertical wind speed was recorded in the PTRMS data to synchronize the clocks of the computers. Only every third hour was allocated for the DEC measurements since the PTR-MS was utilized also in concentration profile and shoot scale emission measurements. Our PTR-MS measurement, calibration, and concentration calculation methods have been described in detail by Taipale et al. (2008).

An infrared gas analyzer (IRGA, LI-COR Inc., LI-6262) was used in the $\mathrm{H}_{2} \mathrm{O}$ measurements. The data were recorded continuously at $10 \mathrm{~Hz}$ on the same computer as the wind data of the DEC measurements, which enabled the conventional EC measurements of $\mathrm{H}_{2} \mathrm{O}$ fluxes. The heated PTFE sampling line was $12 \mathrm{~m}$ in length and $8 \mathrm{~mm}$ in inner diameter. The sampling flow was $13.51 \mathrm{~min}^{-1}$ for the first $10 \mathrm{~m}$ and $12.51 \mathrm{~min}^{-1}$ for the last $2 \mathrm{~m}$. A side flow of $71 \mathrm{~min}^{-1}$ was taken into the IRGA through a PTFE tube, which was $0.5 \mathrm{~m}$ in length and $4 \mathrm{~mm}$ in inner diameter (for details, see Keronen et al., 2003).

\subsection{DEC simulation and M37}

The DEC simulation was based on the $\mathrm{H}_{2} \mathrm{O}$ data from the IRGA. To increase noise, normally distributed random numbers were added to the original time series. The average was not changed whereas the standard deviation was increased by about $13-15 \%$. Figure 1 shows an example of this procedure

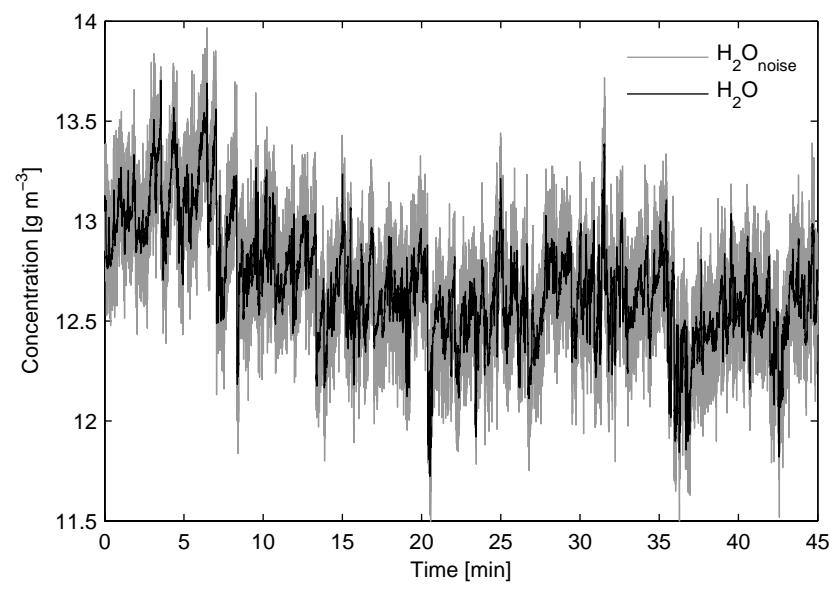

Fig. 1. Example of the original $\mathrm{H}_{2} \mathrm{O}$ measurements with the IRGA and the corresponding manipulated signal containing added noise (9 August 2007 12:00-12:45). The standard deviation of $\mathrm{H}_{2} \mathrm{O}_{\text {noise }}$ is $14 \%$ higher than that of $\mathrm{H}_{2} \mathrm{O}$.

designed to improve the resemblance between the IRGA and PTR-MS measurements. In the later analysis, the manipulated $\mathrm{H}_{2} \mathrm{O}$ signal $\left(\mathrm{H}_{2} \mathrm{O}_{\text {noise }}\right)$ was converted into a disjunct time series using the sampling interval of the actual DEC measurements $(6.6 \mathrm{~s})$. The simulation results, the DEC fluxes of $\mathrm{H}_{2} \mathrm{O}_{\text {noise }}$, were evaluated against the EC fluxes of $\mathrm{H}_{2} \mathrm{O}$.

Although not exclusively dependent on the ambient $\mathrm{H}_{2} \mathrm{O}$ concentration, the PTR-MS water cluster ion signal (M37) can be employed in $\mathrm{H}_{2} \mathrm{O}$ flux measurements (Ammann et al., 2006), provided it is routinely calibrated for $\mathrm{H}_{2} \mathrm{O}$. Our aim was to study how the different lag time methods affect M37 fluxes and whether some of them yield a better correlation with the reference $\mathrm{H}_{2} \mathrm{O}$ fluxes. The only treatment for M37 was the conversion into normalized counts per second (ncps) according to the equation proposed by Taipale et al. (2008).

The correlation between the M37 signal and the $\mathrm{H}_{2} \mathrm{O}$ concentration varied substantially. When calculated for the 45min flux averaging time, typical daytime correlation coefficients were $0.65-0.90$, but nocturnal values were below 0.30 . Hence the EC fluxes of $\mathrm{H}_{2} \mathrm{O}$ were considered a somewhat rough reference and the motivation focused more on the sensitivity of the M37 fluxes to the lag time methods.

\subsection{Covariance functions}

A covariance function gives the covariance of the vertical wind speed and the gas concentration as a function of lag time (e.g. Kaimal and Finnigan, 1994):

$F(\Delta t)=\frac{1}{N} \sum_{i=1}^{N} w^{\prime}\left(i-\Delta t / \Delta t_{w}\right) c^{\prime}(i)$.

Here, $\Delta t$ is the lag time between the wind and concentration measurements, $w^{\prime}=w-\bar{w}$ is the momentary deviation of the vertical wind speed from its average, and $c^{\prime}=c-\bar{c}$ is that of 


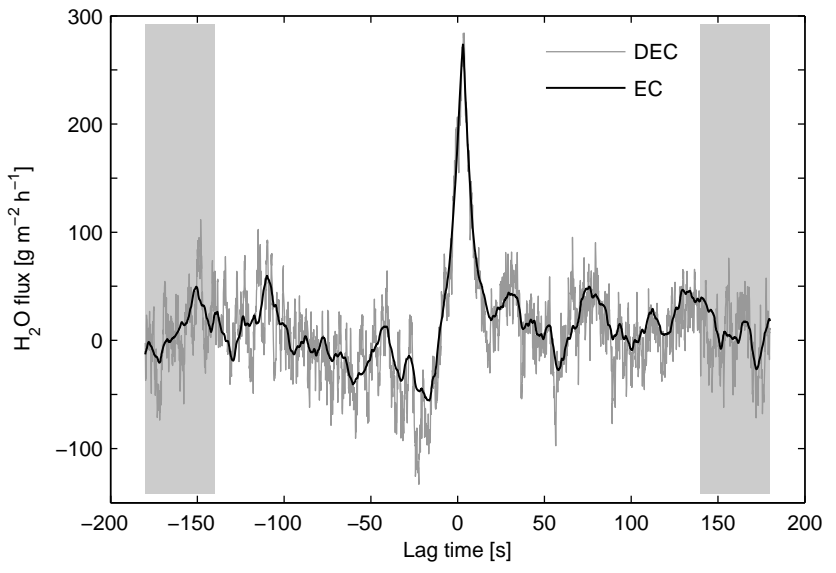

Fig. 2. Covariance function of $\mathrm{H}_{2} \mathrm{O}$ calculated in the EC and DEC manner (9 August 2007 12:00-12:45). The comparison illustrates how DEC increases the noise and thus the flux uncertainty. The shaded areas show the lag time ranges used in the uncertainty estimation, which was based on the standard deviations of the covariance function. Note that only the EC fluxes of $\mathrm{H}_{2} \mathrm{O}$ were used as a reference in the DEC simulation (Sect. 2.2). The DEC version of the covariance function of $\mathrm{H}_{2} \mathrm{O}$ is a mere illustration.

the VOC or $\mathrm{H}_{2} \mathrm{O}$ mass concentration or the normalized M37 count rate. The sampling interval in the wind measurements, $\Delta t_{w}$, was $0.1 \mathrm{~s}$ and the number of measurements during the 45-min flux averaging time, $N$, was 410 in DEC and 27000 in EC.

Covariance functions were calculated in the DEC manner for methanol (M33), monoterpenes (M137), M37, and $\mathrm{H}_{2} \mathrm{O}_{\text {noise }}$, whereas the conventional EC procedure was used for $\mathrm{H}_{2} \mathrm{O}$ (Fig. 2). In all cases, the lag time window was $\pm 180 \mathrm{~s}$ with a time resolution of $0.1 \mathrm{~s}$. Before the calculations, three-dimensional coordinate rotation and linear detrending were applied to the data using established methods (Kaimal and Finnigan, 1994). As the sampling time was $0.5 \mathrm{~s}$ for M33 and M137, five-point running averages of the vertical wind speed were used for these masses. The PTR-MS and anemometer data were synchronized time-wise by finding the sharp maximum from the autocorrelation function of the vertical wind speed. To make the covariance functions of M33, M37, and M137 temporally concordant, the actual measurement times of these masses within the PTR-MS cycle were taken into account.

The flux error estimation was based on the covariance functions. The uncertainty of a flux value was determined by calculating standard deviations from the lag time ranges -180 to $-140 \mathrm{~s}$ and 140 to $180 \mathrm{~s}$ (Wienhold et al., 1994; Spirig et al., 2005). The average of the standard deviations was multiplied by 1.96 to get the $95 \%$ confidence interval for each flux measurement (Rinne et al., 2007). Figure 2 illustrates the increasing effect of DEC on the flux uncertainty when compared with EC.

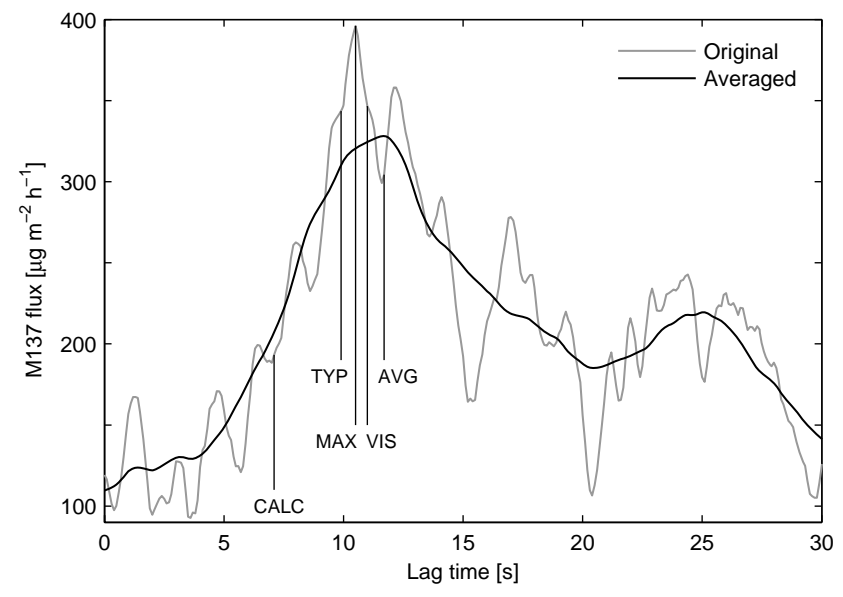

Fig. 3. Principles of the lag time methods illustrated with a covariance function of M137 (11 August 2007 12:00-12:45). The calculated (CALC) and typical (TYP) constant lag times were 7.1 and $9.9 \mathrm{~s}$. In the maximum covariance method (MAX), the lag time was $10.5 \mathrm{~s}$. The averaging approach (AVG) yielded a lag time of $11.7 \mathrm{~s}$, which was determined from the maximum of the averaged covariance function. However, the final flux value was derived from the original covariance function. The visual assessment method (VIS) gave a lag time of $11.0 \mathrm{~s}$.

\subsection{Lag time methods}

The crux of this study was the comparison of five lag time methods. One of them relied on a theoretical constant value, while in the other methods lag times were determined directly from the covariance functions. As the motivation was stand-alone DEC measurements with PTR-MS, this straightforward regime was deemed viable. Also more complex and perhaps better alternatives have been proposed (e.g. Shaw et al., 1998; Massman, 2000), but usually they require spectral analysis and hence high frequency measurements, which makes them unsuitable for DEC.

The lag time methods were based on the following principles (Fig. 3):

- In the CALC method, the lag time was calculated from the sampling flow and the sampling line dimensions. It was kept constant throughout the measurement period. The values were 2.9 and $7.1 \mathrm{~s}$ for the IRGA and PTRMS measurements, respectively.

- Also in the TYP method, the lag time was kept constant over the measurement period. It represented a typical daytime value deduced from the median of five measurements with distinct covariance function maxima. The lag time was $3.3 \mathrm{~s}$ for $\mathrm{H}_{2} \mathrm{O}_{\text {noise }}, 7.2 \mathrm{~s}$ for $\mathrm{M} 33$, $8.2 \mathrm{~s}$ for M37, and $9.9 \mathrm{~s}$ for M137. The objective of this method was to illustrate consequences of considering a limited number of measurements representative of the whole period. 

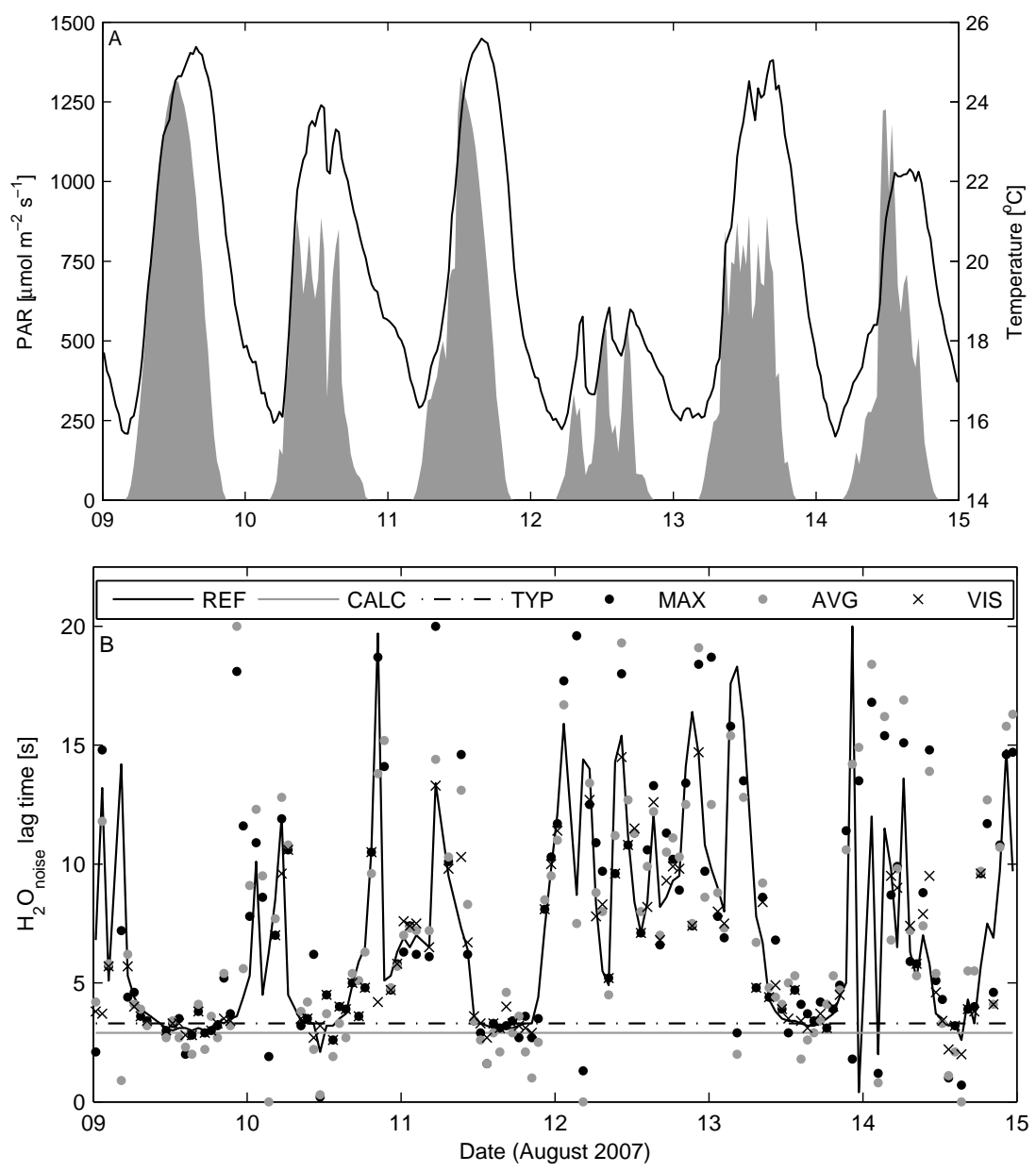

Fig. 4. (A) Photosynthetically active radiation (PAR), air temperature, and (B) lag time of $\mathrm{H}_{2} \mathrm{O}_{\text {noise }}$ as given by the five lag time methods (Sect. 2.4). The lag time of $\mathrm{H}_{2} \mathrm{O}$ (REF) was determined with MAX. The EC fluxes of $\mathrm{H}_{2} \mathrm{O}$ served as a reference in the DEC simulation (see Fig. 5).

- In the MAX method, the lag time was determined from the maximum absolute value of the covariance function within a given lag time window. This is the prevalent method in EC (e.g. Aubinet et al., 2000). It was applied to the reference EC fluxes of $\mathrm{H}_{2} \mathrm{O}$ as well as to the DEC fluxes of $\mathrm{H}_{2} \mathrm{O}_{\text {noise }}$ using a lag time window $0-20 \mathrm{~s}$. The window was $0-50 \mathrm{~s}$ for M33, M37, and M137.

- In our new averaging approach (AVG), the covariance function was first averaged using a five-second running average to make patterns more distinguishable (Fig. 3). The lag time was derived from this averaged covariance function using the MAX method. Although averaging was practised to aid the lag time identification, the final flux value was always determined from the original covariance function at the indicated lag time. This ensured that no part of the real flux signal was eliminated due to the averaging. The width of the averaging window was estimated visually using the EC measurements of $\mathrm{H}_{2} \mathrm{O}$ and the simulated DEC data of $\mathrm{H}_{2} \mathrm{O}_{\text {noise. The chosen }}$ window was deemed wide enough to allow a sufficient noise reduction but also narrow enough to prevent a considerable shift in the covariance function maximum.

- The VIS method was based on manual assessment using the following guidelines. The lag time was determined visually from a figure showing a covariance function for the lag time range -180 to $180 \mathrm{~s}$. This first view gave a general idea of the function patterns and noise. It was zoomed in on the lag time window used in MAX to look for a positive or negative peak with a minimum height of about two times the noise and a minimum base width of about $2-3 \mathrm{~s}$. The lag time was derived from around the middle of the peak, i.e., not necessarily from the maximum. If an unambiguous resolution was impossible, only the flux uncertainty was calculated. 

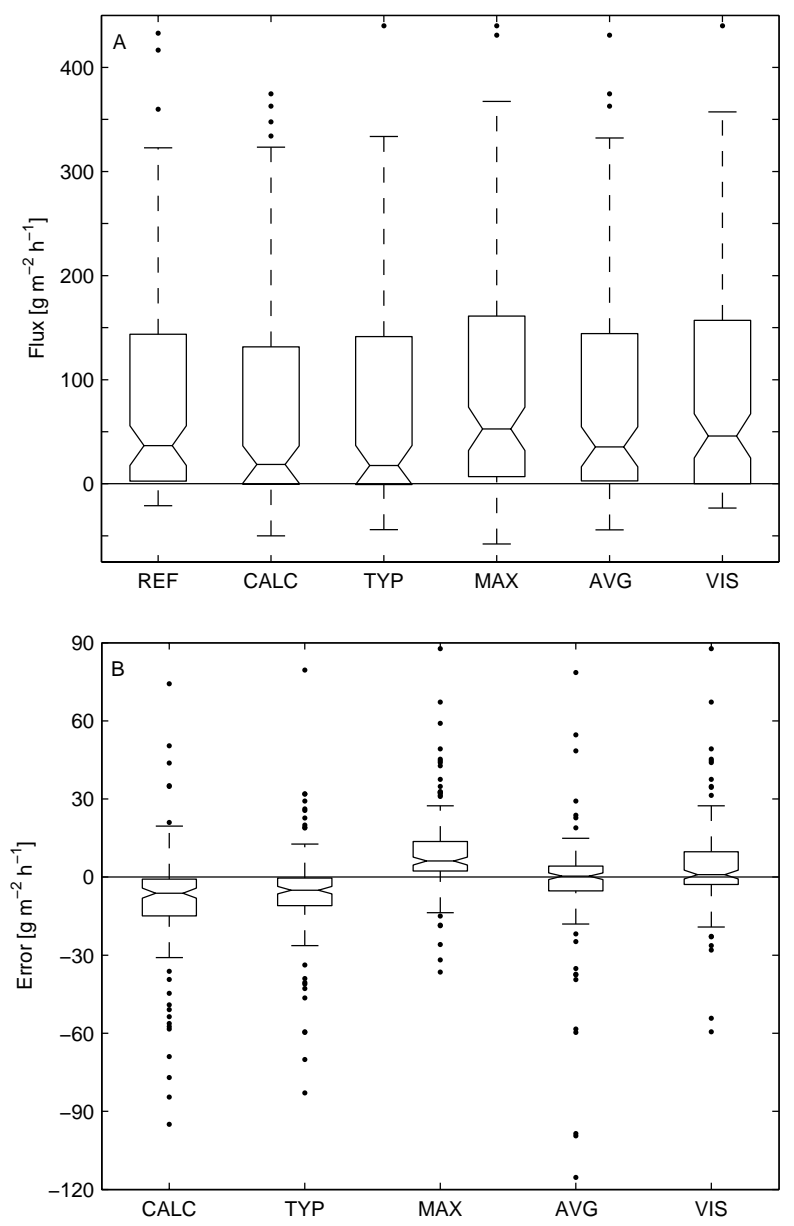

Fig. 5. DEC simulation results. Panel (A) gives the statistics of the DEC fluxes of $\mathrm{H}_{2} \mathrm{O}_{\text {noise }}$ and the EC fluxes of $\mathrm{H}_{2} \mathrm{O}$. Panel (B) shows the error analysis. The DEC fluxes were calculated using the five lag time methods (Sect. 2.4) and evaluated against the reference EC fluxes (REF, Sect. 3.2). The line in the middle of each box is the median. The lower and upper line are the 25 th and 75 th percentile, the distance between them is the interquartile range. The error bars extend from the top or bottom of the box to the furthest data value within 1.5 times the interquartile range. The values beyond the error bars are outliers. The notches show the $95 \%$ confidence interval for the median. If notches of two boxes do not overlap, the difference between medians is statistically significant.

\section{Results and discussion}

The measurement period 9-14 August 2007 contained a fairly wide range of conditions for micrometeorological flux measurements. The friction velocity peaked typically at $0.5-$ $0.9 \mathrm{~m} \mathrm{~s}^{-1}$ in the afternoon and was below $0.25 \mathrm{~m} \mathrm{~s}^{-1}$ between 21:00 and 06:00. This is a general acceptance threshold for flux measurements at the SMEAR II site (Markkanen et al., 2001). The air temperature varied from 15.6 to $25.6^{\circ} \mathrm{C}$ and the daily maximum of photosynthetically active radiation from 550 to $1330 \mu \mathrm{mol} \mathrm{m}^{-2} \mathrm{~s}^{-1}$ (Fig. 4a). It was raining only on 12 August.
To enable an explicit comparison of the lag time methods, all measurements were included in the analysis, i.e., no data were filtered out due to the friction velocity threshold or any other quality criterion. A flux measurement was rated unreliable if the flux uncertainty exceeded the absolute value of the flux. In VIS, the undetermined fluxes were afterwards converted into zeros to allow commensurate median calculations.

\subsection{Lag times}

A survey of the lag times revealed two important features. Figure $4 \mathrm{~b}$ illustrates the variation in the lag time of $\mathrm{H}_{2} \mathrm{O}_{\text {noise }}$ as given by MAX, AVG, and VIS. It also shows the lag time of $\mathrm{H}_{2} \mathrm{O}$ determined with MAX. In general, the daytime values were smaller and fluctuated remarkably less than the night-time values, although the rainy 12 August did not fit into this pattern. Also M33, M37, and M137 exhibited quite similar behaviour (not shown). The substantial hourly and diurnal lag time variation indicates that CALC and TYP indeed are inadvisable options. This was somewhat expected as constant lag time methods are often considered fundamentally flawed (e.g. Massman, 2000). While typically larger than the constant lag times, the medians determined with MAX, AVG, and VIS never differed significantly at the $95 \%$ confidence level. In the case of $\mathrm{H}_{2} \mathrm{O}_{\text {noise }}$, they were also in agreement with the median lag time of $\mathrm{H}_{2} \mathrm{O}$.

The lag times of M33, M37, and M137 gave more insight into VOC flux measurements. Their medians differed slightly despite the same measurement setup and the correction for the actual measurement times within the PTR-MS measurement cycle. The differences were not statistically significant at the $95 \%$ confidence level in MAX and AVG, but M33 differed significantly from both M37 and M137 in VIS. The median lag time was $8.1 \mathrm{~s}$ for M33, $9.8 \mathrm{~s}$ for M37, and $10.5 \mathrm{~s}$ for M137. This suggests that the lag time should be determined individually for each compound, a result which has also been observed in $\mathrm{CO}_{2}$ and $\mathrm{H}_{2} \mathrm{O}$ studies (e.g. Su et al., 2004; Ibrom et al., 2007).

\subsection{DEC simulation results}

To assess the performance of the different lag time methods, we resorted to the $\mathrm{H}_{2} \mathrm{O}$ measurements with the IRGA. Each lag time method was used to determine the DEC fluxes of $\mathrm{H}_{2} \mathrm{O}_{\text {noise }}$, the manipulated $\mathrm{H}_{2} \mathrm{O}$ signal containing added noise (Sect. 2.2). The EC fluxes of $\mathrm{H}_{2} \mathrm{O}$ served as a reference (REF) for this DEC simulation.

Regardless of the lag time method, the correlation between the simulated DEC fluxes and REF was strong. The correlation coefficient ranged from 0.98 to 0.99 . Figure $5 \mathrm{a}$ shows the flux statistics by means of a box plot (e.g. McGill et al., 1978). The median fluxes were 18, 17, 53, 35, and $46 \mathrm{~g} \mathrm{~m}^{-2} \mathrm{~h}^{-1}$ for CALC, TYP, MAX, AVG, and VIS, while the median for REF was $37 \mathrm{~g} \mathrm{~m}^{-2} \mathrm{~h}^{-1}$. As the notches in 

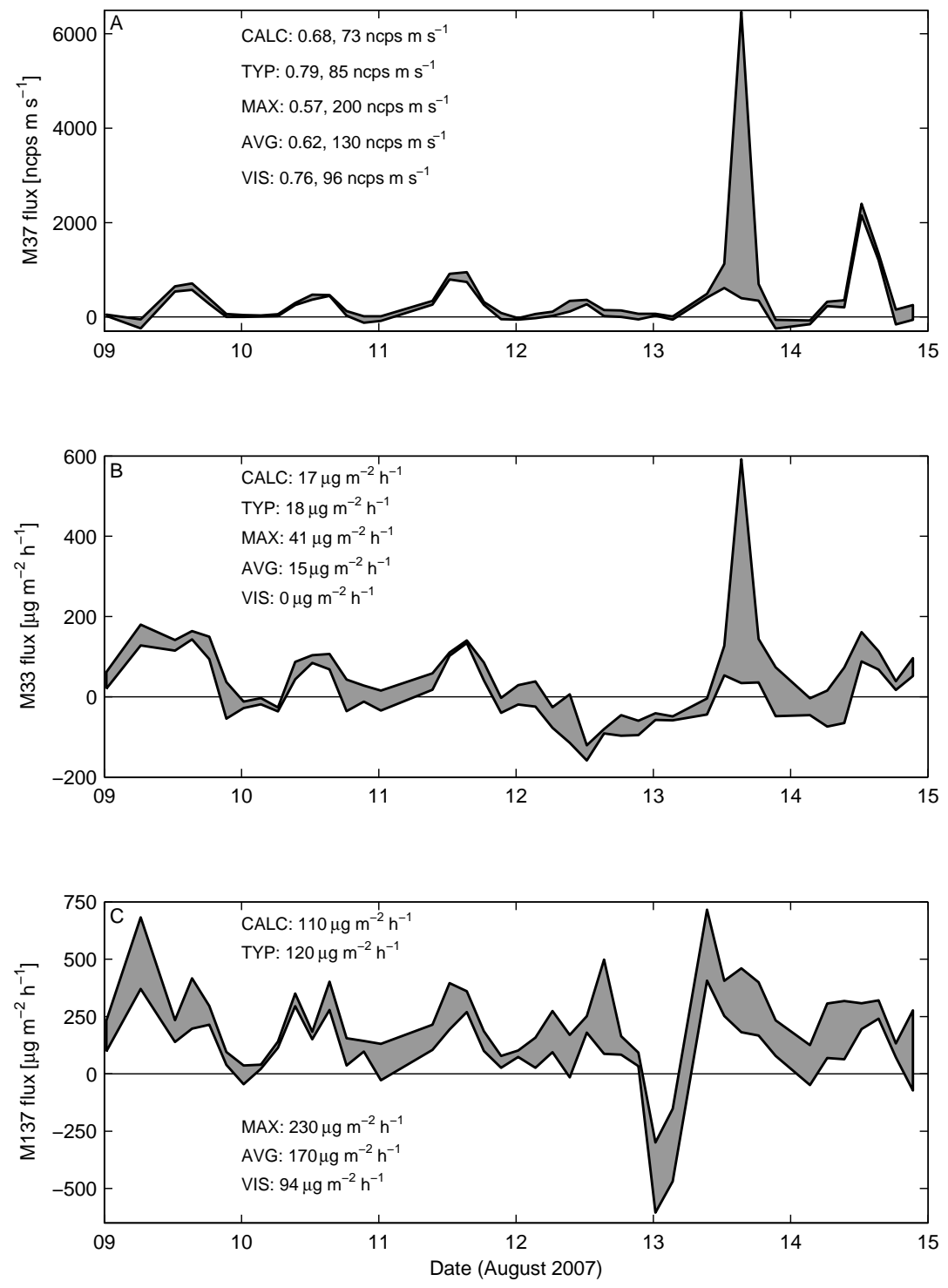

Fig. 6. Range of the M37, M33, and M137 fluxes determined with the five lag time methods (Sect. 2.4). The numbers show the median fluxes and (A) the correlation coefficients between the M37 flux and the reference $\mathrm{H}_{2} \mathrm{O}$ flux.

the REF box overlap with the notches in the other boxes, the difference between the reference value and each median was not statistically significant at the $95 \%$ confidence level. The margin between MAX and CALC as well as MAX and TYP was of borderline significance, otherwise the methods produced quite similar results. The interquartile range (from the 25 th to 75 th percentile) and the $95 \%$ confidence interval of AVG resembled those of REF fairly well. However, the comparison of the flux statistics did not offer conclusive evidence in favour of or against any of the lag time methods.

In contrast, the error analysis shown in Fig. $5 \mathrm{~b}$ reveals substantial information on the method performance. To evaluate tendencies to over- or underestimate absolute fluxes, the error had a binary definition. It was defined as the difference between the simulated DEC flux and the reference EC flux when the reference value was positive or zero. Conversely, the error was the difference between the reference and simulated flux when the reference flux was negative.

Each method had a wide error range, but the interquartile range was more reasonable. The median errors were -6.2 , $-5.0,6.2,0.32$, and $0.97 \mathrm{~g} \mathrm{~m}^{-2} \mathrm{~h}^{-1}$ for CALC, TYP, MAX, AVG, and VIS. As illustrated by the notches, the median error of MAX was significantly higher than the other values, and both CALC and TYP had significantly lower medians than AVG and VIS. Despite the wide error dispersion, AVG had the smallest interquartile range, indicating that it was the most precise of the five methods. 
We can conclude that the median errors of AVG and VIS did not differ from zero at the $95 \%$ confidence level. CALC and TYP underestimated the absolute fluxes and MAX was prone to overestimation. As MAX was based on the maximum absolute covariance, it gave rather systematically higher or lower values than the reference depending on the direction of the flux. This overshooting might explain why MAX had such a high median error. Except for one measurement, it could always resolve the flux reliably, in the sense that the absolute flux exceeded the flux uncertainty. Rather than providing confidence, this probably just reflects the excess nature of the method.

In summary, the DEC simulation indicated that AVG should be regarded as a promising alternative for lag time determination in DEC measurements. Also VIS can serve as a sound lag time method, provided that the amount of data is reasonable. The overshooting character of MAX may cause a considerable positive bias to the absolute flux in DEC measurements where covariance functions tend to be noisy (Fig. 2).

\subsection{Sensitivity of DEC fluxes}

Figure 6 illustrates the effect of the lag time methods on the actual DEC measurements with PTR-MS. The flux range due to the methods varied notably during the measurement period. It was $20-6100 \mathrm{ncps} \mathrm{m} \mathrm{s}^{-1}$ for M37, 6.5$560 \mu \mathrm{g} \mathrm{m}^{-2} \mathrm{~h}^{-1}$ for M33, and $18-410 \mu \mathrm{g} \mathrm{m}^{-2} \mathrm{~h}^{-1}$ for M137. Despite the high momentary deviations, the median fluxes did not differ statistically, except for M137. For it MAX produced a significantly higher result than CALC, TYP, and VIS, while the $95 \%$ confidence interval of AVG overlapped with those of all the other methods.

The correlation between the DEC fluxes of M37 and the EC fluxes of $\mathrm{H}_{2} \mathrm{O}$ was good for each method (Fig. 6a). The correlation coefficient varied between 0.57 and 0.79 . The differences were not significant at the $95 \%$ level, so the correlation analysis did not yield a conclusive result. Like in previous studies (Rinne et al., 2007; Davison et al., 2009), the covariance function of M37 had a visible maximum in most daytime measurements, but the maximum was often indistinguishable at night. Sometimes VIS failed for M37 but not for M33 and M137, or then their lag times differed substantially (Sect. 3.1). Hence it appears that M37 has limited feasibility to act as a tracer in the lag time determination, despite its high potential due to the close correlation with $\mathrm{H}_{2} \mathrm{O}$.

Although not strictly statistically significant, MAX gave the highest median consistently for M37, M33, and M137. As in the DEC simulation, it produced results that could nearly always be rated reliable. This deceptive feature was again due to the maximum-oriented principle of the method.

Based on the flux sensitivity analysis and the DEC simulation, we recommend to be careful when applying MAX to DEC measurements of VOCs. It can cause a remarkable positive bias, even to the median flux, since VOC emission is normally much higher than deposition. We suggest using AVG instead of MAX as the averaging approach does not have such strong appetite for overestimation. Further, AVG is a convenient alternative to VIS as it makes flux calculation more systematic and less labour-intensive.

\section{Conclusions}

We presented a straightforward comparison of five lag time methods to assess their applicability to DEC measurements with PTR-MS. According to the DEC simulation, the constant lag time methods had a tendency to underestimate the absolute values of fluxes, whereas the maximum covariance method was prone to overestimation. The visual assessment method and the averaging approach did not yield statistically significant errors.

The flux sensitivity analysis indicated that the individual measurements were rather sensitive to the lag time methods, but typically this effect averaged out when the median fluxes were considered. Although not always significant, the maximum covariance method consistently produced the highest medians, thus reflecting the excess nature of the method. The feasibility of the constant lag time methods was questionable, as expected, due to the substantial lag time variation over time. The variation within compounds illustrated the importance of compound-specific lag time determination.

It would be wrong to advertise our new averaging approach as flawless and beyond compare. However, this study demonstrated that it can reduce the bias somewhat when contrasted with the customary choice, the maximum covariance method. Given this feature and the potential for automatic flux calculation, we recommend using the averaging method in DEC measurements with PTR-MS.

In principle, the averaging approach is suitable for any eddy covariance application with a low signal-to-noise ratio as long as the width of the averaging window is determined properly. Further studies of its performance in different micrometeorological conditions and with other compounds could reveal new important features.

Acknowledgements. We thank C. Ammann, S. Haapanala, L. Järvi, T. Karl, P. Keronen, I. Mammarella, A. Nordbo, and J.-P. Tuovinen for helpful discussions on the many aspects of the lag time challenge. We also thank M. K. Kajos and J. Patokoski for their assistance in the DEC measurements. We acknowledge the Academy of Finland (projects 120434, 125238, 209216, and 1118615), the European Integrated Project on Aerosol-Cloud-Climate and Air Quality Interactions (EUCAARI), the Helsinki University Centre for Environment (Urban and Rural Air Pollution Consortium), and the Kone Foundation for financial support.

Edited by: M. Weber 


\section{References}

Ammann, C., Brunner, A., Spirig, C., and Neftel, A.: Technical note: Water vapour concentration and flux measurements with PTR-MS, Atmos. Chem. Phys., 6, 4643-4651, doi:10.5194/acp6-4643-2006, 2006.

Aubinet, M., Grelle, A., Ibrom, A., Rannik, Ü., Moncrieff, J., Foken, T., Kowalski, A. S., Martin, P. H., Berbigier, P., Bernhofer, Ch., Clement, R., Elbers, J., Granier, A., Grünwald, T., Morgenstern, K., Pilegaard, K., Rebmann, C., Snijders, W., Valentini, R., and Vesala, T.: Estimates of the annual net carbon and water exchange of forests: The EUROFLUX methodology, Adv. Ecol. Res., 30, 113-175, 2000.

Blake, R. S., Monks, P. S., and Ellis, A. M.: Proton-transfer reaction mass spectrometry, Chem. Rev., 109, 861-896, 2009.

Brunner, A., Ammann, C., Neftel, A., and Spirig, C.: Methanol exchange between grassland and the atmosphere, Biogeosciences, 4, 395-410, doi:10.5194/bg-4-395-2007, 2007.

Claeys, M., Graham, B., Vas, G., Wang, W., Vermeylen, R., Pashynska, V., Cafmeyer, J., Guyon, P., Andreae, M. O., Artaxo, P., and Maenhaut, W.: Formation of secondary organic aerosols through photooxidation of isoprene, Science, 303, 1173-1176, 2004.

Davison, B., Taipale, R., Langford, B., Misztal, P., Fares, S., Matteucci, G., Loreto, F., Cape, J. N., Rinne, J., and Hewitt, C. $\mathrm{N}$.: Concentrations and fluxes of biogenic volatile organic compounds above a Mediterranean macchia ecosystem in western Italy, Biogeosciences, 6, 1655-1670, doi:10.5194/bg-6-16552009, 2009.

de Gouw, J. and Warneke, C.: Measurements of volatile organic compounds in the Earth's atmosphere using proton-transferreaction mass spectrometry, Mass Spectrom. Rev., 26, 223-257, 2007.

Guenther, A., Hewitt, C. N., Erickson, D., Fall, R., Geron, C., Graedel, T., Harley, P., Klinger, L., Lerdau, M., McKay, W. A., Pierce, T., Scholes, B., Steinbrecher, R., Tallamraju, R., Taylor, J., and Zimmerman, P.: A global model of natural volatile organic compound emissions, J. Geophys. Res., 100(D5), 88738892, 1995.

Guenther, A. B. and Hills, A. J.: Eddy covariance measurement of isoprene fluxes, J. Geophys. Res., 103(D11), 13145-13152, 1998.

Hallquist, M., Wenger, J. C., Baltensperger, U., Rudich, Y., Simpson, D., Claeys, M., Dommen, J., Donahue, N. M., George, C., Goldstein, A. H., Hamilton, J. F., Herrmann, H., Hoffmann, T., Iinuma, Y., Jang, M., Jenkin, M. E., Jimenez, J. L., Kiendler-Scharr, A., Maenhaut, W., McFiggans, G., Mentel, Th. F., Monod, A., Prévôt, A. S. H., Seinfeld, J. H., Surratt, J. D., Szmigielski, R., and Wildt, J.: The formation, properties and impact of secondary organic aerosol: current and emerging issues, Atmos. Chem. Phys., 9, 5155-5236, doi:10.5194/acp-95155-2009, 2009.

Hari, P. and Kulmala, M.: Station for Measuring EcosystemAtmosphere Relations (SMEAR II), Boreal Environ. Res., 10, 315-322, 2005.

Hoffmann, T., Odum, J. R., Bowman, F., Collins, D., Klockow, D., Flagan, R. C., and Seinfeld, J. H.: Formation of organic aerosols from the oxidation of biogenic hydrocarbons, J. Atmos. Chem., 26, 189-222, 1997.

Hörtnagl, L., Clement, R., Graus, M., Hammerle, A., Hansel, A., and Wohlfahrt, G.: Dealing with disjunct concentration measure- ments in eddy covariance applications: A comparison of available approaches, Atmos. Environ., 44, 2024-2032, 2010.

Ibrom, A., Dellwik, E., Larsen, S. E., and Pilegaard, K.: On the use of the Webb-Pearman-Leuning theory for closed-path eddy correlation measurements, Tellus, 59B, 937-946, 2007.

Kaimal, J. C. and Finnigan, J. J.: Atmospheric Boundary Layer Flows, Oxford University Press, Inc., New York, USA, 1994.

Kaimal, J. C. and Gaynor, J. E.: The Boulder Atmospheric Observatory, J. Clim. Appl. Meteorol., 22, 863-880, 1983.

Karl, T., Guenther, A., Jordan, A., Fall, R., and Lindinger, W.: Eddy covariance measurement of biogenic oxygenated VOC emissions from hay harvesting, Atmos. Environ., 35, 491-495, 2001.

Karl, T. G., Spirig, C., Rinne, J., Stroud, C., Prevost, P., Greenberg, J., Fall, R., and Guenther, A.: Virtual disjunct eddy covariance measurements of organic compound fluxes from a subalpine forest using proton transfer reaction mass spectrometry, Atmos. Chem. Phys., 2, 279-291, doi:10.5194/acp-2-279-2002, 2002.

Keronen, P., Reissell, A., Rannik, Ü., Pohja, T., Siivola, E., Hiltunen, V., Hari, P., Kulmala, M., and Vesala, T.: Ozone flux measurements over a Scots pine forest using eddy covariance method: performance evaluation and comparison with fluxprofile method, Boreal Environ. Res., 8, 425-443, 2003.

Kiendler-Scharr, A., Wildt, J., Dal Maso, M., Hohaus, T., Kleist, E., Mentel, Th. F., Tillmann, R., Uerlings, R., Schurr, U., and Wahner, A.: New particle formation in forests inhibited by isoprene emissions, Nature, 461, 381-384, doi:10.1038/ nature08292, 2009.

Koppmann, R., ed.: Volatile Organic Compounds in the Atmosphere, Blackwell Publishing Ltd, Oxford, UK, 2007.

Lenschow, D. H., Mann, J., and Kristensen, L.: How long is long enough when measuring fluxes and other turbulence statistics?, J. Atmos. Ocean. Tech., 11, 661-673, 1994.

Lindinger, W., Hansel, A., and Jordan, A.: On-line monitoring of volatile organic compounds at pptv levels by means of ProtonTransfer-Reaction Mass Spectrometry (PTR-MS) - Medical applications, food control and environmental research, Int. J. Mass Spectrom., 173, 191-241, 1998.

Markkanen, T., Rannik, Ü., Keronen, P., Suni, T., and Vesala, T.: Eddy covariance fluxes over a boreal Scots pine forest, Boreal Environ. Res., 6, 65-78, 2001.

Massman, W. J.: A simple method for estimating frequency response corrections for eddy covariance systems, Agr. Forest Meteorol., 104, 185-198, 2000.

McGill, R., Tukey, J. W., and Larsen, W. A.: Variations of box plots, Am. Stat., 32(1), 12-16, 1978.

McMillen, R. T.: An eddy correlation technique with extended applicability to non-simple terrain, Bound.-Lay. Meteorol., 43, 231-245, 1988.

Müller, M., Graus, M., Ruuskanen, T. M., Schnitzhofer, R., Bamberger, I., Kaser, L., Titzmann, T., Hörtnagl, L., Wohlfahrt, G., Karl, T., and Hansel, A.: First eddy covariance flux measurements by PTR-TOF, Atmos. Meas. Tech., 3, 387-395, doi:10.5194/amt-3-387-2010, 2010.

Rinne, H. J. I., Guenther, A. B., Warneke, C., de Gouw, J. A., and Luxembourg, S. L.: Disjunct eddy covariance technique for trace gas flux measurements, Geophys. Res. Lett., 28(16), 3139-3142, 2001.

Rinne, J., Taipale, R., Markkanen, T., Ruuskanen, T. M., Hellén, H., Kajos, M. K., Vesala, T., and Kulmala, M.: Hydrocarbon 
fluxes above a Scots pine forest canopy: measurements and modeling, Atmos. Chem. Phys., 7, 3361-3372, doi:10.5194/acp-73361-2007, 2007.

Rinne, J., Douffet, T., Prigent, Y., and Durand, P.: Field comparison of disjunct and conventional eddy covariance techniques for trace gas flux measurements, Environ. Pollut., 152, 630-635, 2008.

Shaw, W. J., Spicer, C. W., and Kenny, D. V.: Eddy correlation fluxes of trace gases using a tandem mass spectrometer, Atmos. Environ., 32, 2887-2898, 1998.

Shimizu, T.: Practical applicability of high frequency correction theories to $\mathrm{CO}_{2}$ flux measured by a closed-path system, Bound.Lay. Meteorol., 122, 417-438, doi:10.1007/s10546-006-9115-z, 2007.

Spirig, C., Neftel, A., Ammann, C., Dommen, J., Grabmer, W., Thielmann, A., Schaub, A., Beauchamp, J., Wisthaler, A., and Hansel, A.: Eddy covariance flux measurements of biogenic VOCs during ECHO 2003 using proton transfer reaction mass spectrometry, Atmos. Chem. Phys., 5, 465-481, doi:10.5194/acp-5-465-2005, 2005.

Su, H.-B., Schmid, H. P., Grimmond, C. S. B., Vogel, C. S., and Oliphant, A. J.: Spectral characteristics and correction of longterm eddy-covariance measurements over two mixed hardwood forests in non-flat terrain, Bound.-Lay. Meteorol., 110, 213-253, 2004.
Taipale, R., Ruuskanen, T. M., Rinne, J., Kajos, M. K., Hakola, H., Pohja, T., and Kulmala, M.: Technical Note: Quantitative long-term measurements of VOC concentrations by PTR-MS measurement, calibration, and volume mixing ratio calculation methods, Atmos. Chem. Phys., 8, 6681-6698, doi:10.5194/acp8-6681-2008, 2008.

Turnipseed, A. A., Pressley, S. N., Karl, T., Lamb, B., Nemitz, E., Allwine, E., Cooper, W. A., Shertz, S., and Guenther, A. B.: The use of disjunct eddy sampling methods for the determination of ecosystem level fluxes of trace gases, Atmos. Chem. Phys., 9, 981-994, doi:10.5194/acp-9-981-2009, 2009.

Warneke, C., Luxembourg, S. L., de Gouw, J. A., Rinne, H. J. I., Guenther, A. B., and Fall, R.: Disjunct eddy covariance measurements of oxygenated volatile organic compounds fluxes from an alfalfa field before and after cutting, J. Geophys. Res., 107(D8), 4067, doi:10.1029/2001JD000594, 2002.

Wienhold, F. G., Frahm, H., and Harris, G. W.: Measurements of $\mathrm{N}_{2} \mathrm{O}$ fluxes from fertilized grassland using a fast response tunable diode laser spectrometer, J. Geophys. Res., 99(D8), 1655716567, 1994. 